\title{
Efeitos de oralidade na retórica pliniana
}

\author{
ALCEU DIAS LIMA \\ FCL Faculdade de Ciências e Letras \\ UNESP - Universidade Estadual Paulista \\ Câmpus de Araraquara-SP
}

\begin{abstract}
RESUMO: Reflexões como as deste breve artigo, seguidas, conforme é o caso, de um texto, uma carta de autor antigo, aduzida à guisa de exemplo, visam a mostrar o interesse que elas representarão ou poderão representar no encaminhamento das questões referentes ao conhecimento desses autores por parte dos modernos. O pressuposto é o de que essa forma de consideração procure trabalhar com o conceito de efeito de sentido tal como concebido, por exemplo, na Semiótica Greimasiana, onde ele recebe formulação teórica bastante clara, ou, pelo menos, desenvolvida o suficiente para não ser confundida com o próprio sentido, que recebe, por sua vez, formulação à parte.
\end{abstract}

PALAVRAS-CHAVE: Efeito de sentido; ensino (de língua antiga); oralidade.

Os que trabalhamos com textos do passado clássico temos um fundamento a mais para o desenvolvimento da discussão metalingüística sobre oralidade, porquanto nosso trato com as línguas antigas está limitado, no que concerne ao assunto linguagem objeto, à recepção escrita. Os elementos de que dispomos, portanto, para a abordagem do assunto só podem ser poucos, saltuários, indiretos e aproximativos, uma vez que inferidos dos próprios escritos remanescentes. Daí as sérias consequiências para as questões do ensino deles no que concerne a método, trate-se da aquisição internalizada do simples enunciado frasal, ou dos problemas mais complexos envolvendo os discursos, principalmente na sua feição retórica e poética, com particular atenção aos problemas da métrica, e mais tudo que respeita à prosódia e em geral ao plano da expressão. Daí, em especial, a preocupação com o correto encaminhamento da questão, uma vez que só quando conduzida pelos devidos trâmites é que dela se podem esperar bons resultados em matéria de entendimento dos textos em grego e latim maternos dos respectivos povos (o assunto não será diferente ao estar em causa o sânscrito, mesmo que aí se devam levar em conta especificidades de uso dos textos que o representam).

Oral por definição, a língua não perde seu status prosódico nem mesmo quando mediatizada por conjuntos gráficos ou sistemas de escrita, pois estes são sempre representações visuais de unidades fonológicas e prosódicas preexistentes. Pouco importa a professores das línguas sem falantes naturais a dependência irrecorrível desse tipo de mediadores: é sempre na pressuposição da existência de sujeitos enunciadores e receptores naturais - logo, 
de uma oralidade fundamental - que trabalham. Isso é possível, não obstante a dificuldade histórica apontada, porque, como diz o filósofo, "olhando para letras, que são sinais de sons da linguagem, compreendemos sem mais o que lemos, sem ter necessidade de ouvir os sons; só pessoas que não sabem ler correntemente precisam, para compreender as palavras, emitir os sons de que se compõem" (Hegel, 1944, p. 53).

Essa constatação, por mais que possa parecer ingênua, leva-nos a pensar, por um lado, que não é só a substância fônica, de base acústica, que constitui os sinais distintivos da língua, justificando-se, aí, em sua plenitude, a verificação, segundo a qual o significante, constituído pelas diferenças entre os fonemas, é também de natureza psíquica e, por outro, que, como decorrência de falantes nativos do latim, ou seja, daquele povo cuja vida quotidiana se identificou, como quer Benveniste, com a desse idioma, não estanca a sua criatividade, pouco importa se o que ele nos tem a dizer não nos redime da condição de interlocutores silenciosos, mesmo quando, por estrita necessidade da exposição dos fatos na sala de aula, nos postamos como se falantes fôssemos.

Faz-se, neste ponto, necessária uma ressalva, a de que nem sempre é com a cautela recomendada pela prudência e a verdade que humanistas se comportam em matéria de pronúncia. É até comum tropeçar-se, quando do trato com as Humanidades, na auto-suficiência de mestres de dicção, diante dos quais não sobra ao despreparado aprendiz mais do que a inconseqüente admiração sem indagação e, pior, sem crítica.

Aos que se disponham a trilhar novos caminhos, em atitude menos conformista, não parece impertinente apontar, desde que não se ponha o carro adiante dos bois, aquele cujos desbravadores vêm sendo, na esteira de Saussure, Hjelmslev, Benveniste, Greimas e outros e que se orienta de acordo com os princípios formais há pouco indicados. Com esses, será proveitoso entabular um diálogo profícuo como o que segue: ainda que esteja fora do nosso alcance um padrão prosódico oral empírico para as línguas antigas, com fundamento, por exemplo, no latim falado quotidianamente pelos romanos do século I a.C., e ainda que tenhamos, por isso, que contentar-nos em matéria de pronúncia e prosódia, com as poucas indicações subministradas pelos filólogos, poucas, imprecisas e, sobretudo, incapazes de eliminar indesejáveis, mas de todo inevitáveis efeitos de interferências modernas. Apesar disso tudo, é sobre prosódia que se há de alicerçar, por uma considerável parte, a descrição da língua latina e, com mais forte razão, da poesia de quem teve essa língua antiga por idioma materno.

É quando se tem em conta a natureza psíquica, diferencial, não substancial da prosódia enquanto fato de língua que passam a ser compreensíveis propósitos como os do crítico, ao escrever: "a prosódia ... não é mais que o repositório do tempo no interior da língua" (Brodsky, 1994, p.45). Entende-se também por aí, isto é, por essa característica formal do significante, por qual motivo "a prosódia sempre sobrevive à história" (Ibidem). Assim, aquilo que até há relativamente bem pouco tempo vinha sendo tratado por sua face menos formal - a da fonética - pode passar a ser o que há de mais sutilmente efetivo na linguagem verbal, além de ser o que melhor responde ao voto de Ovídio:

ad mea perpetuum deducite tempora carmen (Metamorfoses, I, 4) ("dai aos meus dias um canto imortal"), 
desde que elevado a tratamento lingüístico pela fonologia.

O exemplo tomado à poesia não é, neste escrito, simples questão de oportunidade, é antes exigência metodológica do que se está chamando tratamento lingüístico. Mesmo para quem admite que enquanto "meio de comunicação poética", o signo verbal, "à diferença do modo de expressão da prosa, torna-se teoricamente um fim em si e em conseqüência disso deve ser formulado" (Ovídio, I, 4), continua válido sustentar, sobretudo depois do advento da fonologia, o princípio do isomorfismo entre a expressão e o conteúdo (Hegel, 1944, p. 51).

Não há, com efeito, contradição entre a exigência de formulação teórica específica para o discurso poético - de vez que a descrição preconizada para ambos os planos é feita sobre pressupostos lingüísticos - e a homologação deles conseqüente a essa descrição, pois se deve levar em conta que o princípio da descrição de qualquer dos planos e da própria homologação é o da expressividade da linguagem verbal.

Lembrando: 1. com Hjelmslev, que "todo texto, contanto que não seja reduzido demais para ser base suficiente de dedução do sistema generalizável a outros textos, contém, de hábito, derivados que repousam sobre sistemas diferentes" (Hjelmslev, 1968-71, p.145.); 2. com muita insistência, que "o mérito de uma tradução não se encontra nunca no aproveitamento que fizer das transferências autorizadas entre dois sistemas; está, isto sim, na sensibilidade com que trate as preferências do uso, no convívio, nem sempre pacífico, com seu sistema"; 3. sem esquecer aquele que é entre nós cânon dos mais produtivos, o de que "A tradução é a procura de um equivalente e não de um substituto. Requer pelo menos uma afinidade estilística, quando não psicológica" (Brodsky, 1994, p. 84), segue-se em língua portuguesa, à guisa de validação destas considerações, um texto, uma carta, que pretende ser, como texto, o equivalente do original latino de Plínio, autor da segunda metade do século I a.D., início do século II. Insiste-se em que se trata de texto escrito, no qual os simulacros de oralidade - as marcas da presença do destinador e do destinatário no próprio texto, mediante o emprego até insistente das pessoas gramaticais não conseguem disfarçar outras marcas bem mais acentuadas, reveladoras dos hábitos do escritor tanto quanto do retórico:

\section{PLÍNIO, Cartas, V. 8.}

"Meu caro Titínio Capitão,

Saudações.

Você insiste em que eu escreva história. E não está sozinho ao insistir. Muitos me têm recomendado isso amiúde, e eu mesmo o quero, não por achar que a tarefa se cumprirá sem mais, até porque é temerário, você sabe, encará-la sem o devido preparo, mas porque para mim bonito antes de tudo é não deixarmos cair no olvido aqueles de quem
PLINIUS, Epistulae, V. 8.

C. Plinius Titinio Capitoni suo. S.

Suades ut historiam scribam, et suades non solus, multi hoc me saepe monuerunt, et ego uolo, non quia commode facturum esse confidam (id enim temere credas nisi expertus), sed quia mihi pulchrum in primis uidetur non pati occidere quibus aeternitas 
perpetuar a memória é o nosso dever, prolongando assim, com a dos outros, a nossa própria fama.

2 A mim de fato nada traz tanta inquietação quanto o amor e o desejo de úma longa vida, a coisa mais digna do homem, daquele, em especial, cuja consciência limpa não tema o juízo dos pósteros. 3 Fico então dia e noite me perguntando se é

'por aí que eu vou poder também sair do chão,' (Virg. Georg., 3.8)

pois isso satisfaz, por certo, às minhas ambições, ficando fora do meu alcance aquilo de

'voar na voz dos homens, vencedor...' (Virg. Georg., 3.9),

'ainda que, oxalá!...' (Virg., Aen., 5. 195).

Mas basta aquilo que, pode-se dizer, a história, ela só, parece oferecer. 4 De fato, a uma peça oratória, a um poema falta graça, sem os lavores da arte verbal; história, ao invés, como quer que se escreva mantém seu charme. Pois homens são curiosos por natureza e, por mais singelo que seja o teor de uma notícia, deixam-se levar, como alguém que se faça enrolar até por lorotas e contos da carochinha.

$5 \mathrm{O}$ que me impele, porém, nessa vocação, ainda, é um exemplo de família. Meu tio materno, aquele mesmo que por adoção foi o meu pai, escreveu, e com que escrúpulo, história. Está nos sábios que a coisa mais bonita é seguir os passos dos seus antepassados, desde que nos tenham precedido no reto caminho. 6 Por que então hesitar? Defendi longas e intrincadas causas. Estas eu debeatur aliorumque famam cum sua extendere. 2 Me autem nihil aeque ac diuturnitatis amor et cupido sollicitat, res homine dignissima, eo praresertim qui nullius sibi conscius culpae posteritatis memoriam non reformidet. 3 Itaque diebus ac noctibus cogito: si "qua me quoque possim tollere humo", id enim uoto meo sufficit. Illud supra uotum, "uictorque uirum uolitare per ora... Quamquam o..." Sed hoc satis est, quod prope sola historia polliceri uidetur. 4 Orationi enim et carmini parua gratia, nisi eloquentia est summa; historia quoque modo scripta delectat. Sunt enim homines natura curiosi et quamlibet nuda rerum cognitione capiuntur, ut qui sermunculis etiam fabellisque ducantur.

Me uero ad hoc studium impellit domesticum quoque exemplum. 5 Auunculus meus idemque per adoptionem pater historias et quidem religiosissime scripsit. Inuenio autem apud sapientis honestissimum esse maiorum uestigia sequi, si modo recto itinere praecesserint. 6 Cur ergo cunctor? egi magnas et graues causas; has, etiam si mihi tenuis ex iis spes, destino retractare, ne tantus ille labor meus, nisi hoc quod reliquum est studii addidero, mecum pariter intercidat. 7 Nam si rationem posteritatis habeas, quidquid non 
pretendo retocar, mesmo que grande coisa não espere delas, a fim de que tamanho trabalho, por falta desse derradeiro esforço, não fique truncado com a minha morte. 7 Pois, aos olhos da posteridade, o que não foi acabado vale tanto quanto o não começado. Alguém me dirá: "Você pode, ao mesmo tempo, retocar seus discursos e escrever história." Assim fosse! Na verdade, uma e outra tarefa são tão árduas que já seria proeza bastante levar a cabo uma só. 8 Aos dezenove anos, comecei a falar no foro e só agora é que vejo, e ainda assim de modo indistinto, que saber o orador deve dominar. 9 Que acontecerá, se a essa tarefa uma nova se sobrepuser? Eloqüência e história têm sem dúvida muito em comum mas é onde tudo parece estar em comum que mais divergências se descobrem. Aquela narra? Esta também, mas de modo diferente: a esta convém de preferência assunto sem destaque, sem brilho e com apelo popular, àquela são os mais recônditos, fulgurantes e destacados que melhor quadram; 10 nesta ficam bem ossos, músculos, nervos, naquela, certos pormenores e até um penacho; esta muito se compraz com a violência, o travo, o último alento, aquela, com o golpe estudado, o jeito e até certa doçura; em suma, outras palavras, outra sonoridade, outro arranjo. 11 Pois interessa muito, como quer Tucídides, saber de que se trata: da disputa dum prêmio? de firmar prestígio? Desses dois, o primeiro é eloquiência, o outro, história.

De semelhantes causas é que para mim se impõe não aproximar nem misturar dois assuntos díspares e, por sua própria imensidão, tão diversos, a fim de que, obnubilado por essa espécie de mistura, eu não trate numa o que devia tratar na outra. Sendo assim, para não recuar do meu propósito, peço um tempo para decidir.

12 Você, porém, desde já vá pensando por que época devo de preferência começar. Pela est peractum, pro non inchoato est. Dices: "Potes simul et rescribere actiones et componere historiam." Vtinam! sed utrumque tam magnum est, ut abunde sit alterum efficere.

8 Vndeuicensimo aetatis anno dicere in foro coepi et nunc demum quid praestare debeat orator, adhuc tamen per caliginem, uideo. 9 Quid, si huic oneri nouum accesserit? habet quidem oratio et historia multa communia, sed plura diuersa in his ipsis quae communia uidentur. Narrat illa, narrat haec, sed aliter; huic pleraque humilia et sordida et ex medio petita, illi omnia recondita, splendida, excelsa conueniunt; 10 hanc saepius ossa, musculi, nerui, illam tori quidam et quasi iubae decent; haec uel maxime ui, amaritudine, instantia, illa tractu et suauitate atque etiam dulcedine placet; postremo alia uerba, alius sonus, alia constructio. 11 Nam plurimum refert, ut Thucydides ait, ktema sit an agônisma; quorum alterum oratio, alterum historia est.

His ex causis non adducor ut duo dissimilia, et hoc ipso diuersa quod maxima, confundam misceamque, ne tanta quasi collunione turbatus ibi faciam quod hic debeo; ideoque interim ueniam, ut ne a meis uerbis recedam, aduocandi peto. $12 \mathrm{Tu}$ 
antiga, narrada por outros escritores? A investigação está preparada, compô-la é que não é fácil. Pela que não se narrou, a recente? É muito risco para pouca compreensão. 13 Pois fora o fato de que, sendo tão grandes os defeitos dos homens, sobra mais o que condenar do que louvar, além disso, no louvor, acharão que fui mesquinho, na condenação, exagerado, mesmo que tenha sido pródigo nos elogios e rigorosamente imparcial nas minhas críticas. 14 Mas não é isso que me retém, coragem diante da verdade é o que não me falta. O que lhe peço é que, ao aconselhar-me, você seja direto na indicação do caminho e na escolha do assunto, para evitar que, estando eu já pronto para escrever, tenha de ver-me às voltas com algum bom motivo de hesitação e demora.

Adeus." tamen iam nunc cogita quae potissimum tempora aggrediar. Vetera et scripta aliis? parata inquisitio, sed onerosa collatio. Intacta et noua? grarues offensae, leuis gratia. 13 Nam praeter id quod in tantis uitiis hominum plura culpanda sunt quam laudanda, tum, si laudaueris, parcus, si culpaueris, nimius fuisse dicaris, quamuis illud plenissime, hoc restrictissime feceris. 14 Sed haec me non retardant (est enim mihi pro fide satis animi), illud peto, praesternas ad quod hortaris eligasque materiam, ne mihi iam scribere parato alia rursus cunctationis et morae iusta ratio nascatur. Vale.

\section{Referências bibliográficas}

BRODSKY, J. Menos que Um. São Paulo: Companhia das Letras, 1994. HEGEL, G.W. Esthétique. Paris: Edições Montaigne, 1944.

HJELMSLEV, L. Prolégomènes à une théorie du langage. Paris: Minuit, 1968-1971.

OVÍDIO, N. Le Matamorfosi. Bolonha: Zanichelli, 1956.

PLÍNIO, o Jovem. Lettres. Paris: Les Belles Lettres, 1955.

LIMA, Alceu Dias. Effets d'oralité dans la rhétorique plinienne. Classica, São Paulo, 13/ 14 , p. 375-380, 2000/2001.

RESUMÉ: Des reflexions telles que celles de ce petit article, suivies, comme c'est ici le cas, d'un texte d'auteur ancien, ajouté à titre d'exemple, ont pour but de montrer l'intérêt qu'elles peuvent représenter pour la connaissance moderne de ces auteurs. Cela suppose que ce genre de considérations soit en mesure de travailler, entre autres, avec le concept d'effet de sense, tel qu'il est défini, par exemple, par la sémiotique de Greimas, chez qui il trouve une formulation assez claire, au point qu'il n'y risque pas d'être confondu avec le sens lui-même.

MOTS-CLÉS: Effet de sens; enseignement (des langues anciennes); oralité. 